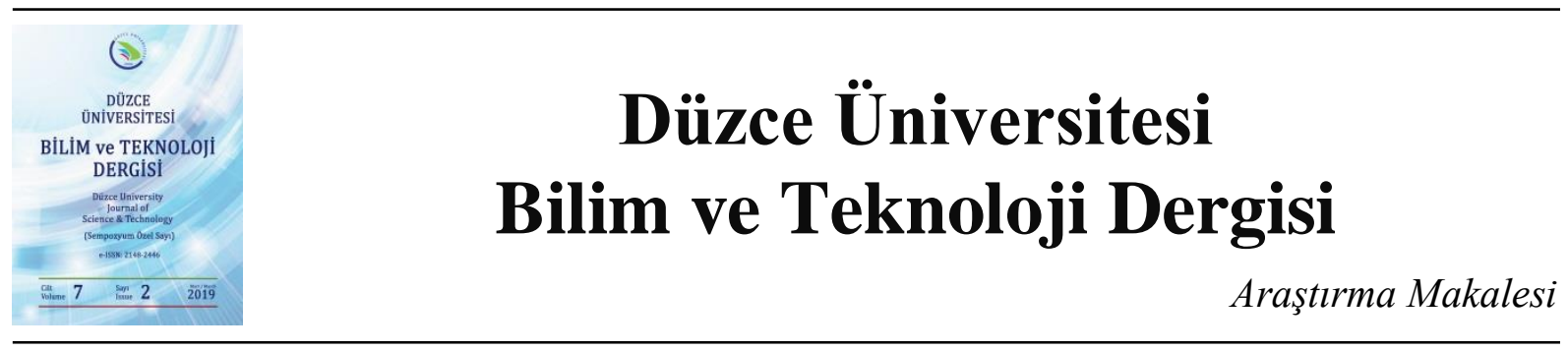

\section{H Tipi Hidrolik Pres Gövdesinin Yapısal Analizi ve Optimizasyonu}

\author{
Fatih Mehmet Mesut ELMAS ${ }^{\text {a }}$, Osman Nuri TURHAN ${ }^{\mathrm{a}}$, Murat DILMEÇ $^{\mathrm{a}, *}$ \\ ${ }^{a}$ Necmettin Erbakan Üniversitesi, Mühendislik ve Mimarlk Fakültesi, Makine Mühendisliği Bölümü, Konya \\ * Sorumlu yazartn e-posta adresi: muratdilmec@konya.edu.tr
}

\begin{abstract}
ÖZET
Sac metal şekillendirme proseslerinde kullanılan presler, işlenecek parça boyutlarının büyük olması, büyük presleme kuvveti ve strok ihtiyacından dolayı büyük ebatlara sahip olmaktadırlar. Sac metal işleme preslerinin gövde imalatında döküm yöntemini kullanmak zordur. Bu nedenle belirli kalınlıkta sac plakalar kaynak yöntemi ile birleştirilerek pres gövdesi oluşturulmaktadır. Ancak çoğu zaman gövdeyi oluşturan plakaların kalınlıkları tecrübi olarak ve gereğinden fazla kullanılmaktadır. Bu çalışmada, sonlu elemanlar analizi kullanılarak 300 ton kapasiteli H tipi pres gövdesinin nümerik kalınlık optimizasyonu yapılmıştır. Böylece pres gövdesini oluşturan plakaların kalınlıkları azaltılmış ve malzeme tasarrufu sağlanmıştır.
\end{abstract}

Anahtar Kelimeler: H tipi hidrolik pres, Sonlu elemanlar yöntemi, Kalınlı optimizasyonu

\section{Structural Analysis and Optimization of H Type Hydraulic Press}

\begin{abstract}
The presses used in forming the sheets have large sizes due to their large part sizes and the need for high pressing force and stroke. It is very difficult to use the casting method in the production of such press bodies. Therefore, each of the members constituting the press body is manufactured separately by combining sheet metal plates of a certain thickness with the welding. However, in most cases the thickness of the plates forming the body is used experimentally and excessively. In this paper, thickness optimization of the $\mathrm{H}$ type press machine capacity of 300 tons has been realized. In this study, thickness optimization of $\mathrm{H}$ type hydraulic press frame has been conducted by using finite element analysis. So, thicknesses of the plate create press frame has been decreased and material saving has been ensured.
\end{abstract}

Keywords: H type hydraulic press, Finite element method, Thickness optimization

Geliş: 08/05/2018, Düzeltme: 23/07/2018, Kabul: 13/11/2018 


\section{GiRISS}

$\mathrm{H}_{s}$ idrolik presler günümüzde kontrol kolaylığı, ekonomik olması ve az yer kaplamalarından dolay1 geniş bir uygulama alanı bulmaktadır [1-4]. Hidrolik presler, elektrik motorundan aldığı dönme hareketini mekanik işe çeviren makinalardır [5-6]. Üzerine bağlanan kalıplar yardımıyla metal iş parçası üzerine basınç ya da darbe uygulayarak metalleri kesmeye, kıvırmaya, çekmeye ya da sıvamaya çalışırlar [7-9].

Ülkemizde pres imalatı yapan firmalar, maliyetinin \%70'ini malzemenin oluşturduğu bu preslerde gereğinden fazla malzeme kullanmaktadırlar. Bazen de uygun olmayan tasarımdan dolayı pres gövdesinde çatlama, kırılma ve plastik şekil değiştirme ortaya çıkabilmektedir. Bu durumda presler kullanışsız hale gelebilmekte ve kalıplar da bozulabilmektedir. Literatürde presler ile ilgili çeşitli araştırmalar yapılmıştır. Arslan [10] bir eksantrik pres gövdesinin yapısal analiz etmiştir. Yağbasan [11] C tipi bir pres gövdesinin sonlu elemanlar yöntemi ile analizini gerçekleştirmiştir.

$\mathrm{Bu}$ çalışmada 300 ton kapasiteli $\mathrm{H}$ tipi pres gövdesinin nümerik kalınlık optimizasyonu sonlu elemanlar analizi kullanılarak yapılmıştır. Bu sayede pres gövdesini oluşturan plakaların kalınlıkları azaltılarak malzeme tasarrufu sağlanmıştır. Presin lineer statik analizinin gerçekleştirilmesinde Ansys Workbench sonlu elemanlar paket programı kullanılmıştır. Presin gövdesinde St37 adlı malzeme kullanılmıştır. Çözümü kolaylaştırmak için geometri de uygun olduğundan modelin $1 / 4$ simetri olarak incelenmiştir.

\section{MATERYAL VE YÖNTEM}

$\mathrm{Bu}$ çalışmada, endüstriyel 300 ton kapasiteli $\mathrm{H}$ tipi hidrolik presin gövdesinin (Şekil 1) kalınlık optimizasyonu için analizler yapılmıştır. Bu analizler sonunda gövdeyi oluşturan plakalara gelen gerilmeleri bulabilmek için statik analizler yapılmış ve gövdeyi oluşturan elemanlar optimize edilmiştir. Pres gövdesinde kullanılan malzemeye ait mekanik özellikler Tablo-1'de ve analizi gerçekleştirilen prese ait teknik özellikler Tablo-2'de verilmiştir.

Tablo 1. St37 malzemenin mekanik özellikleri

\begin{tabular}{ccccc}
\hline Akma mukavemeti & $\begin{array}{l}\text { Çekme } \\
\text { mukavemeti }\end{array}$ & Elastisite modülü & Poisson oranı & Yoğunluk \\
\hline $235 \mathrm{MPa}$ & $370 \mathrm{MPa}$ & $2 \mathrm{E}+11 \mathrm{~Pa}$ & 0,3 & $7800 \mathrm{~kg} / \mathrm{m}^{3}$ \\
\hline
\end{tabular}

Tablo 2. 300 ton kapasiteli hidrolik presin teknik özellikleri

\begin{tabular}{cccc}
\hline Kapasite & Tabla ölçüsü & Strok & Gövde ağırlığı \\
\hline 300 Ton & $1100 \times 1200$ & $800 \mathrm{~mm}$ & $8280 \mathrm{~kg}$ \\
\hline
\end{tabular}




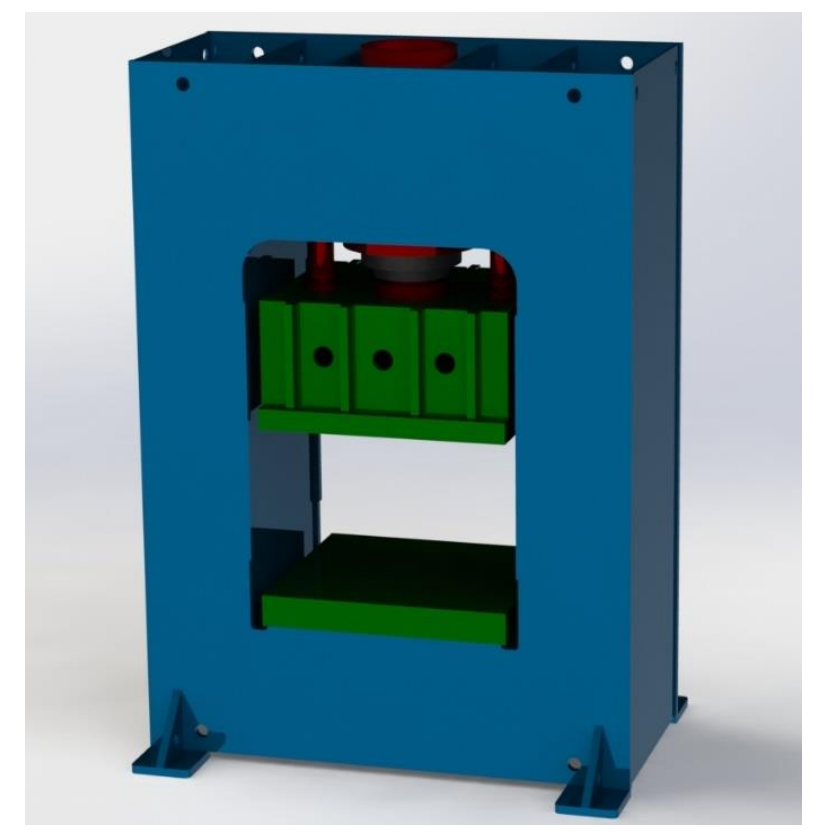

Şekil 1. 300 ton kapasiteli hidrolik presin CAD modeli

Hidrolik pres gövdesinin CAD modeli oluşturulmuştur (Şekil 2). Çözüm süresini azaltmak için pres çeyrek olarak modellenmiştir.

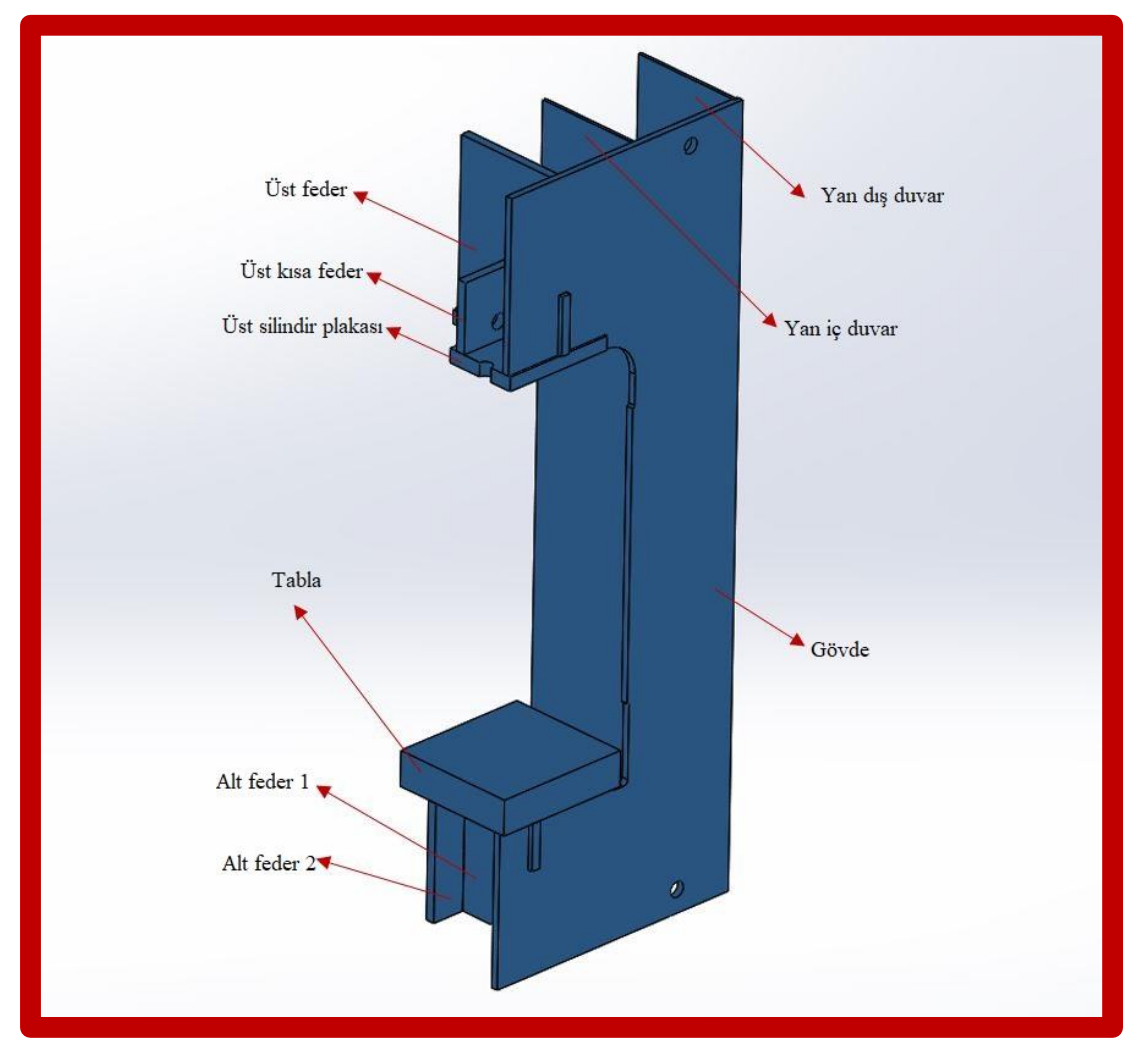

Şekil 2. Basitleştirilen hidrolik pres gövdesinin CAD modeli

Daha sonra presi oluşturan elemanlar sonlu elemanlar ağına (mesh) bölünmüştür (Şekil 3). Statik analizde mesh yöntemi olarak Hex Dominant yöntemi kullanılmış ve mesh geometrisi olarak dörtgen 
eleman seçilmiştir. Ancak bazı bölgelerde uygun geçişi sağlayabilmek için üçgen elemanlar kullanılmıştır.

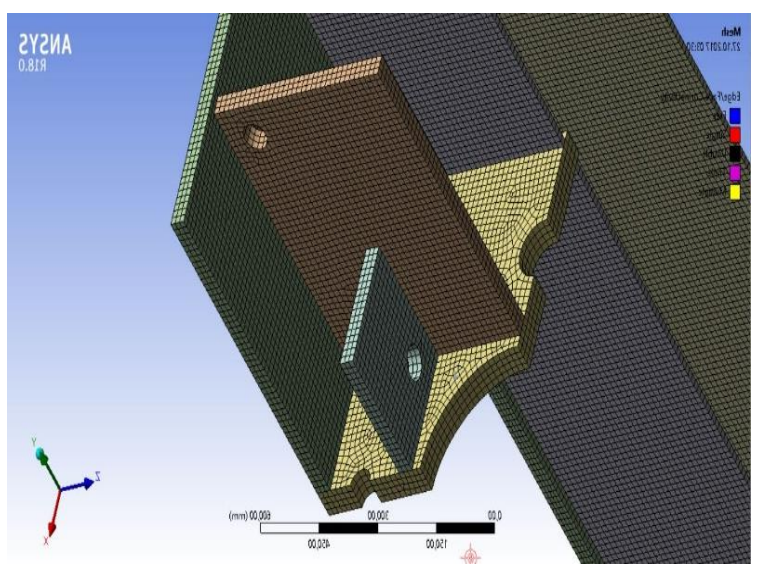

Şekil 3. Hidrolik pres gövdesi mesh geometrisi

Hidrolik pres gövdesi hidrolik silindirlerin gövde ile bağlantısını sağlayan flanşlardan ve stampanın metal malzemeyi sıkıştırmasıyla tablaya aktarılan yüklerle zorlanmaktadır. Yani preste bulunan 1 ana ve 2 yardımcı silindir flanşlarına yükler gelmektedir. Ana silindir 260 ton ve yardımcı silindirler 20 'şer ton yük uygulamaktadır (Şekil 4). 11/4 simetri kullanıldığından yükler de 1/4 oranda uygulanmıştır.

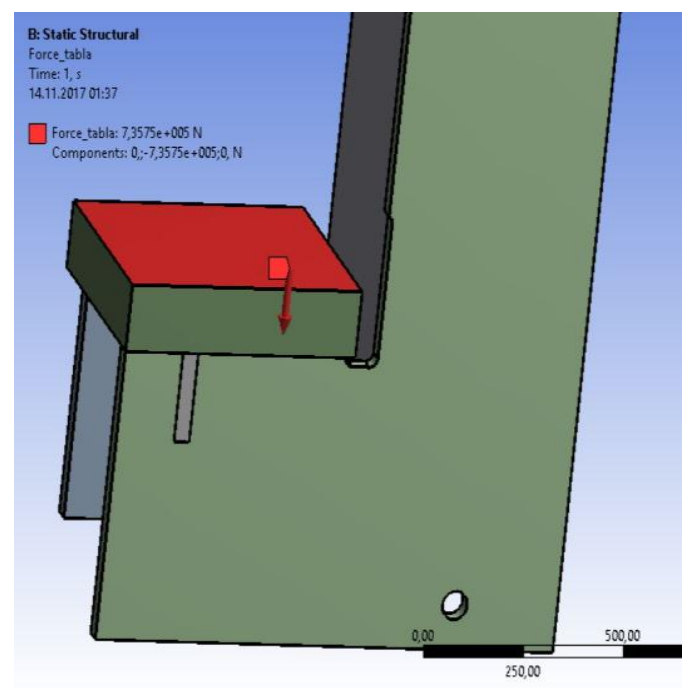

(a)

Şekil 4. (a) Hidrolik pres gövdesi tablanin yüzeyine, (b) hidrolik pres gövdesi yardımct silindire ve (c) hidrolik pres gövdesi koç silindir flanşına uygulanan 


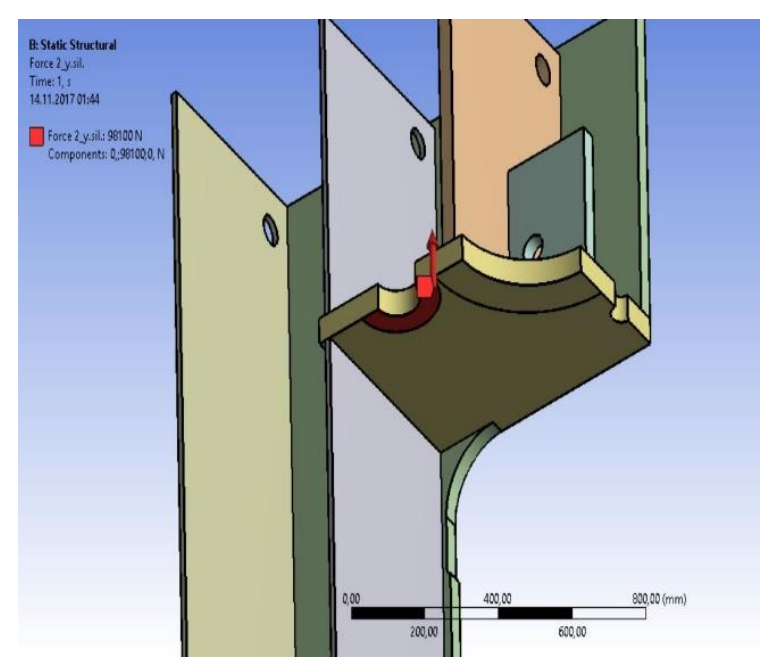

(b)

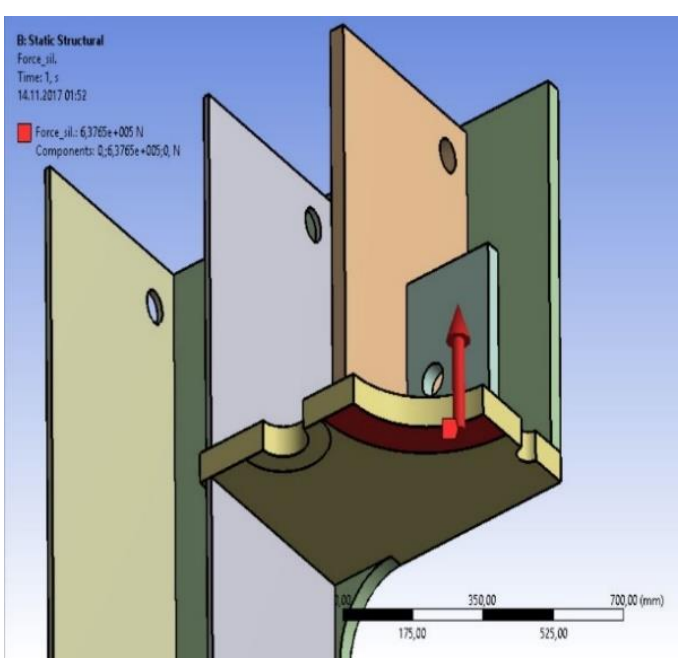

(c)

Şekil 4.(devam.) (a) Hidrolik pres gövdesi tablanın yüzeyine, (b) hidrolik pres gövdesi yardımcı silindire ve (c) hidrolik pres gövdesi koç silindir flanşına uygulanan yükler

Pres gövde modelindeki parçaları mesh yapıldıktan ve yükleri tanımladıktan sonra sınır koşulları tanımlanmıştır. Presin zeminle olan sınır koşulu için 6 serbestlik derecesi de sınırlandırılmışıtır. $R_{x}, R_{y}$ ve $R_{z}$ tam sınırlandırılarak dönme eksenleri kilitlenir. $T_{y}$ sınırlandırılarak zeminden içeri geçmesi önlenir. $T_{x}$ ve $T_{z}$ için küçük yer değiştirmeler serbest bırakılarak, hidrolik presin zeminle kayar bağlantısı ve tüm plakalar arasında kaynak bağlantısı tanımlanır.

Optimizasyonda, bütün parçaların kalınlığı sabit tutulup sadece tablanın kalınlığı düşürüldü ve max gerilmenin değişmediği gözlemlendi, en optimum kalınlık bulununca kadar bu işlem tamamlanarak optimizasyon işlemi gerçekleştirildi.

\section{BULGULAR VE TARTIȘMA}

Analiz sonucu elde edilen Von Mises gerilme sonuçları ile kritik bölgeler belirlenmiş ve bu bölgelerde malzeme kalınlıklarında optimizasyon yapılmışır. Optimizasyon sonucunda 1,25 gibi kabul edilebilir düzeyde [12] emniyet katsayısı elde edilmiştir. Analizlerde elde edilen yer değiştirme sonuçları modelin sınır şartlarına uygunluğunu ve analizin doğruluğunu gösterecektir.

Pres gövdesine bağlanan tablanın köşe kenarlarındaki gerilme değeri Şekil 5'te görüldüğü gibi maksimum değer olan $210 \mathrm{MPa}$ değerindeki bölge noktasal seviyededir ve maksimum gerilme genel olarak turuncu bölgenin değeri olan yaklaşı $185 \mathrm{MPa}$ olarak elde edilmiştir. Ancak bu bölgedeki keskin kenar tekrarlı yüklerdeki mukavemeti artırmak için yuvarlanacaktır.

Şekil 6'daki radyuslu bölge geometrisi itibariyle eğilmeye maruz kaldığından ve çentik etkisine sebep olabilecek bir bölge olduğundan, bu bölgenin merkezinde gerilmenin yüksek elde edilmesi normaldir. $\mathrm{Bu}$ sebeple, bu bölge yorulma, tasarım revizyonu işlemlerinde detaylı incelenmesi gereken bir bölgedir. 


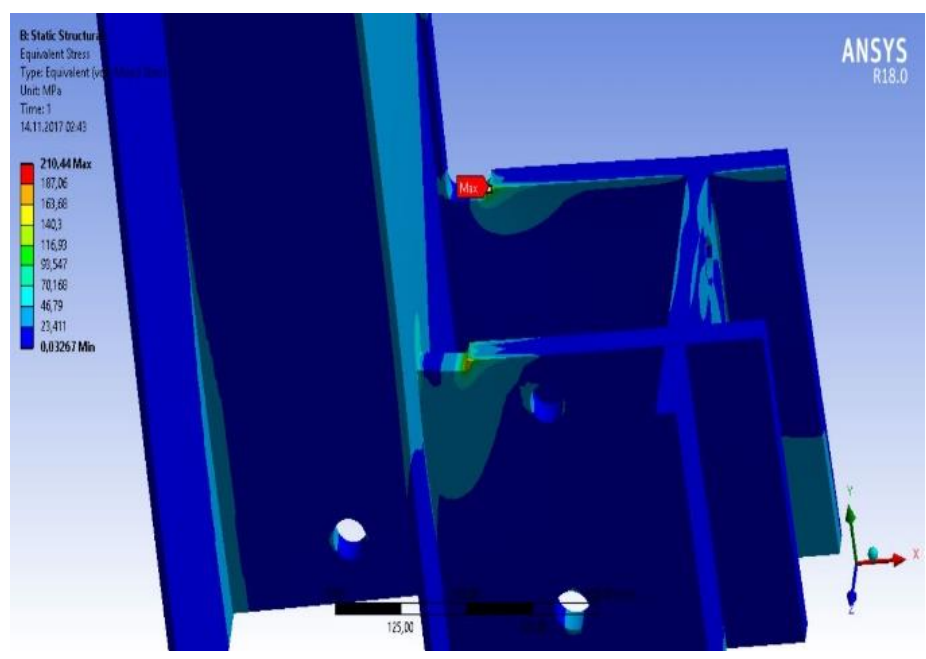

Şekil 5. Hidrolik pres gövdesi Von Mises gerilmesi max. bölge

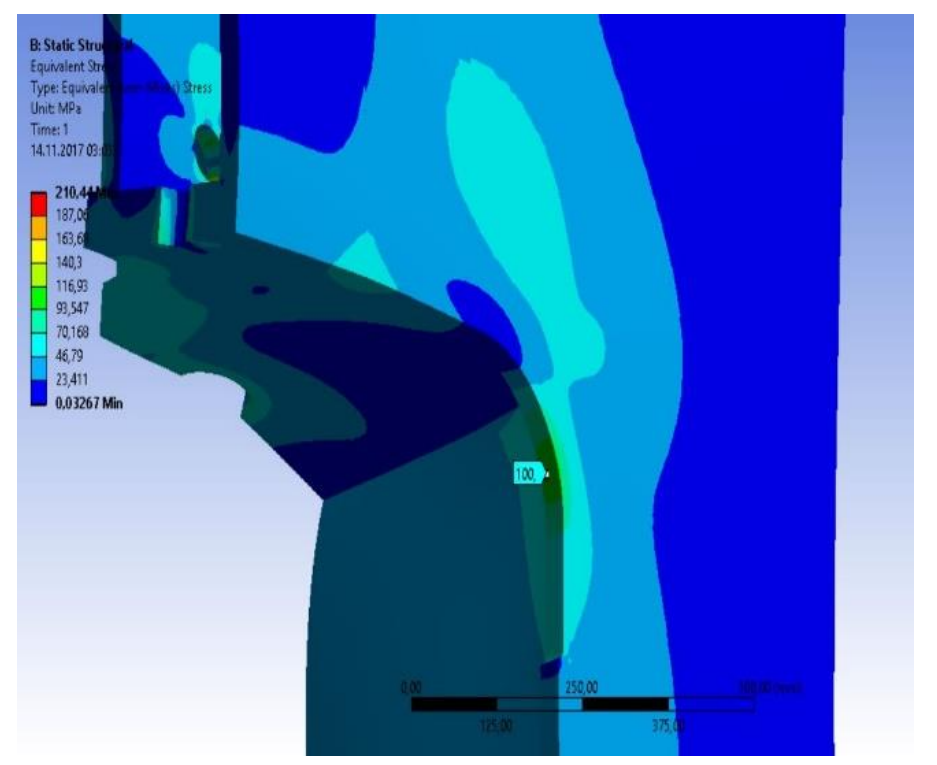

Şekil 6. Hidrolik pres gövdesi Von Mises gerilmesi kritik bölge

Şekil 7'de üst silindirin plakasına montajlı federlerin deliklerinde ve montaj edilen yüzeylerinde yaklaşık $145 \mathrm{MPa}$ bir gerilme oluşmuştur. Bu federin kalınlığında optimizasyon yapılarak federin optimum geometrisi elde edilebilir.

Şekil-8'de görüldüğü gibi, maksimum yer değiştirme koç silindirinin gövdeye bağlandığı kısımda oluşmuştur. Bu yer değiştirmeyi silindir plakasının üstündeki federler sınırlamaktadır. Bu bölgedeki toplam maksimum yer değiştirme miktarı $0,89 \mathrm{~mm}$ olarak belirlenmiştir. Gövde uzunluğunun 3300 mm olduğu göz önüne alındığında, bu değer yüksek değildir. Toplam yer değiştirme değeri azaltılması için, federlerin bağlantı yüzleri artırılabilir. 


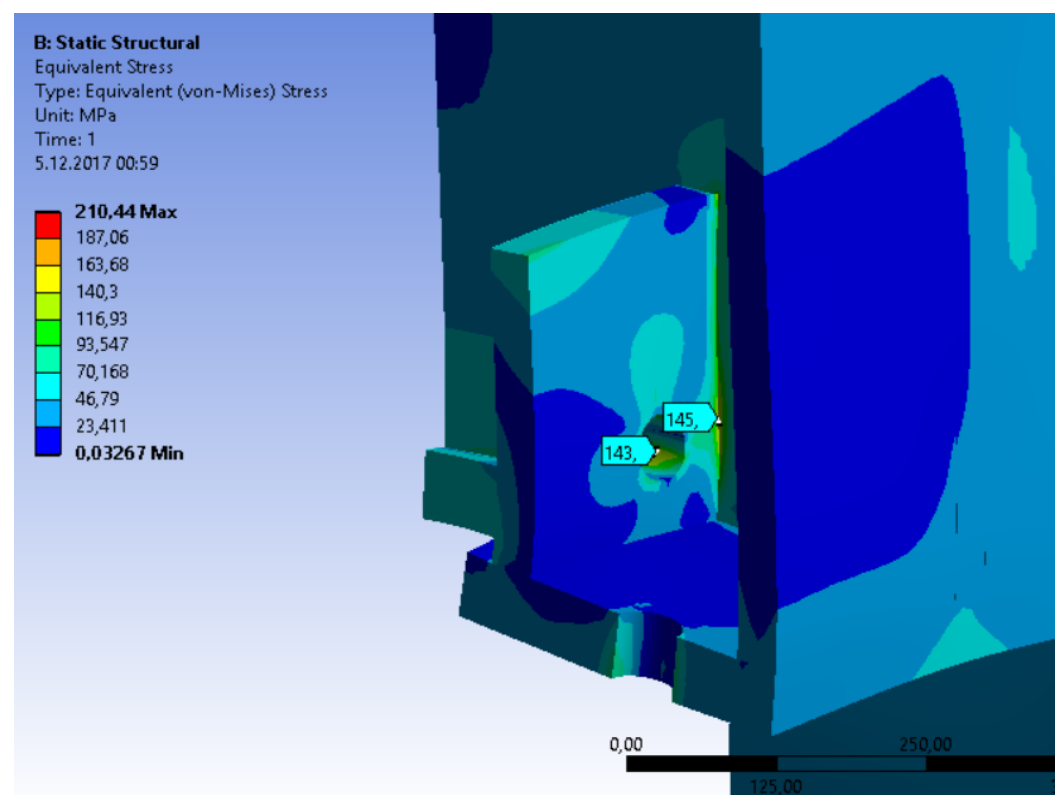

Şekil 7. Hidrolik pres gövdesi Von Mises gerilmesi kritik bölge 2

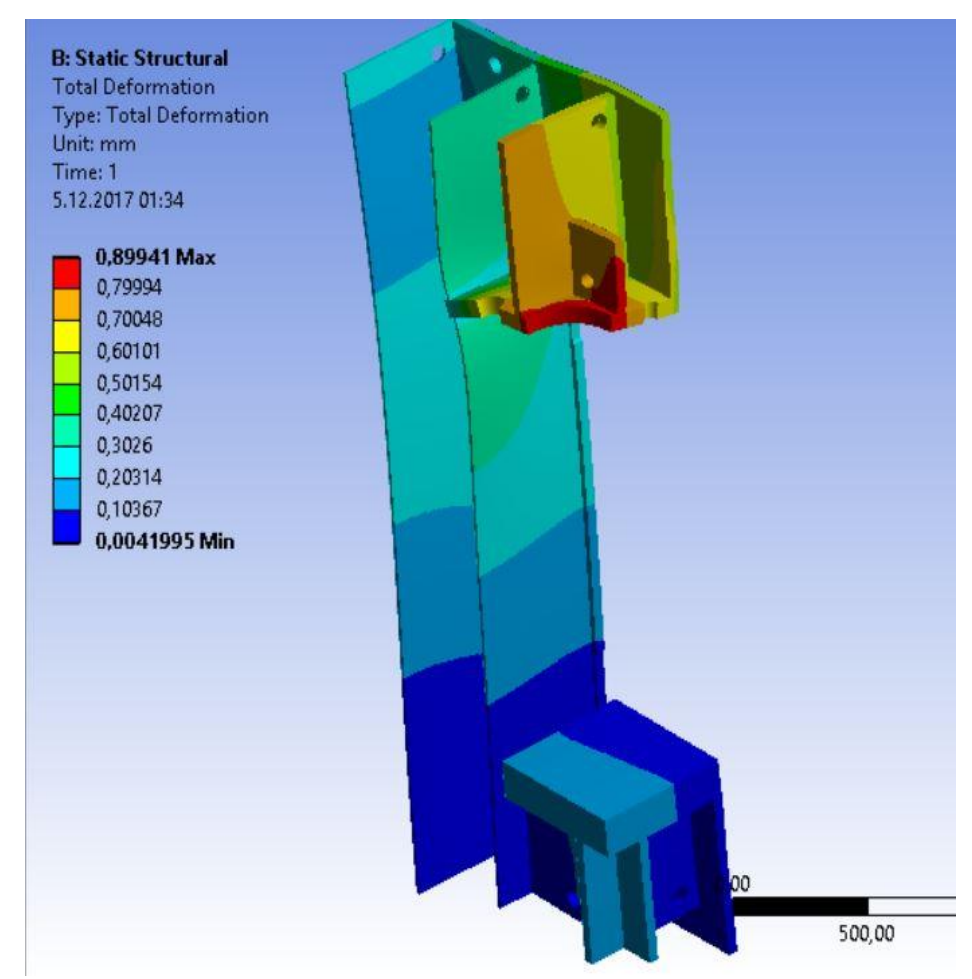

Şekil 8. Hidrolik pres gövdesi toplam yer değiş̧tirme

Şekil 9'da analiz sonucu elde edilen emniyet katsayısı değerleri görülmektedir. Pres gövdesinin emniyet katsayısı max. gerilme olan $185 \mathrm{MPa}$ 'a göre hesaplanmıştır ve 1,27 civarındadır. Emniyet katsayısının 1-5 arasında olduğu bölgelerde gerekli optimizasyon yapılarak emniyet katsayısının minimum 1,2 olması hedeflenmiştir [12].

Emniyet katsayısı 5 değerinin üzerinde kalan mavi ve yeşil bölgeler geometrinin genelini kapsamaktadır. Kalınlık ve ağılık optimizasyonları yapılarak bu değerler düşürülmüştür. 
Şekil 10 ve Şekil 11'de optimizasyon sonrası hidrolik pres gövdesi Von Mises gerilmesi kritik bölgeleri ve Şekil 12'de optimizasyon sonrası hidrolik pres gövdesi toplam yer değiştirme sonuçları gösterilmiştir.

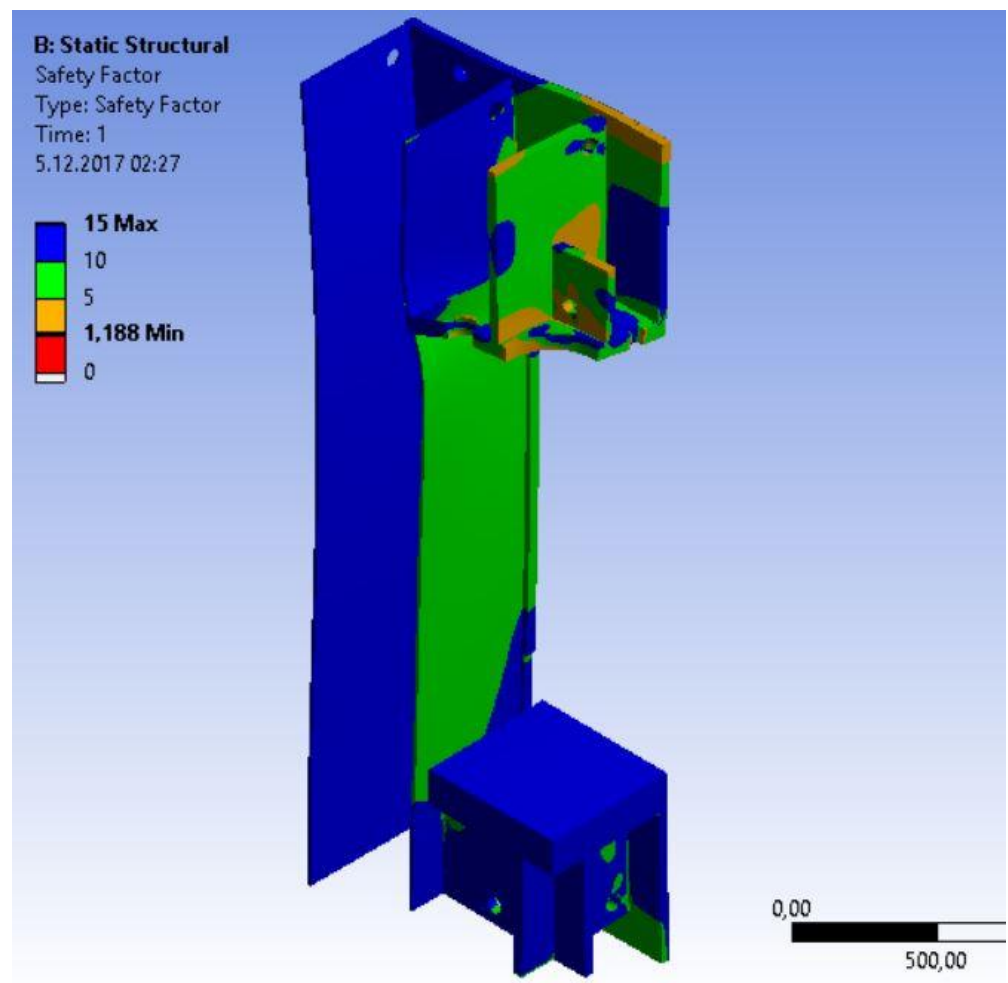

Şekil 9. Hidrolik pres gövdesi emniyet katsayısı

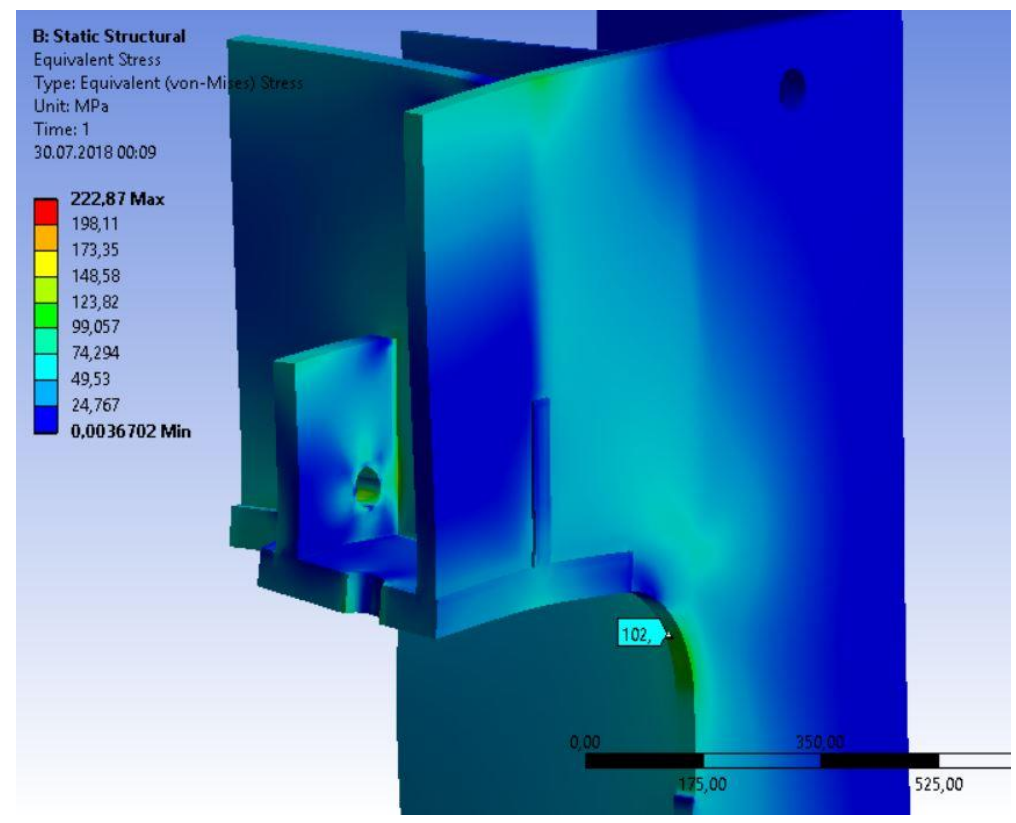

Şekil 10. Optimizasyon sonrası hidrolik pres gövdesi Von Mises gerilmesi kritik bölge 


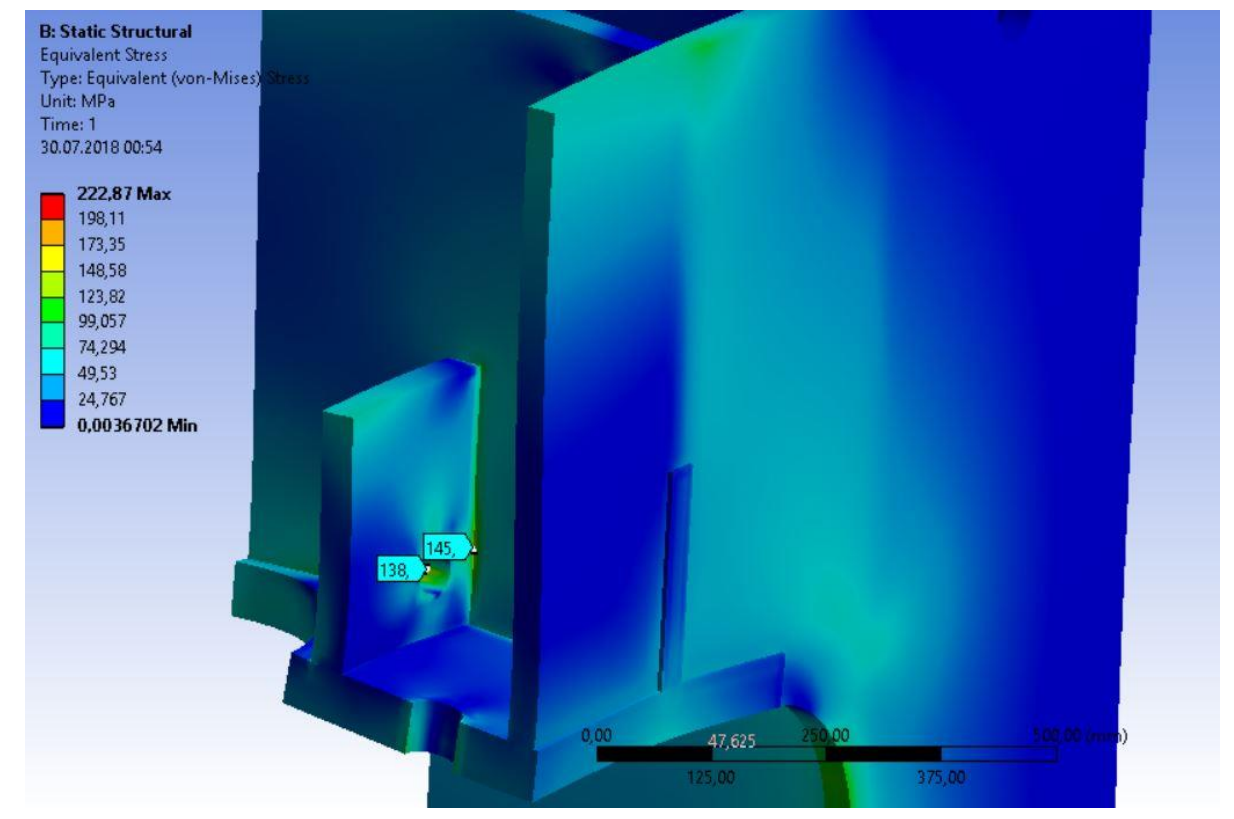

Şekil 11. Optimizasyon sonrası hidrolik pres gövdesi Von Mises gerilmesi kritik bölge 2

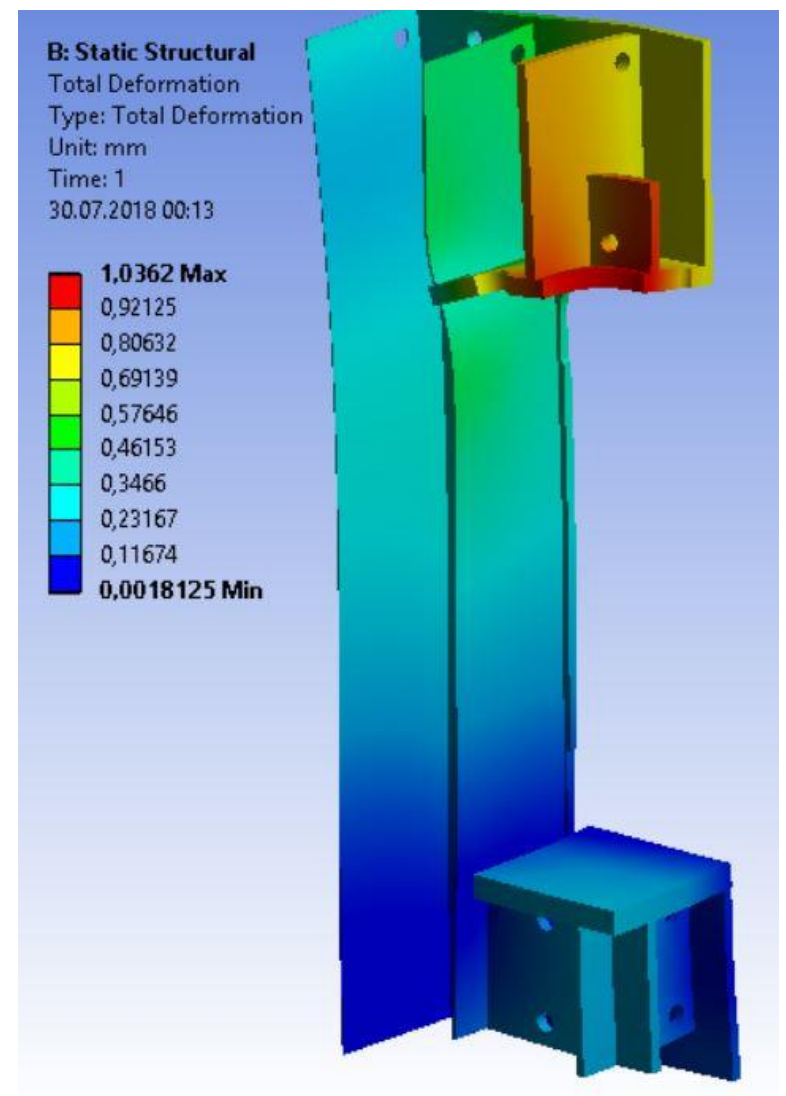

Şekil 12. Optimizasyon sonrası hidrolik pres gövdesi toplam yer değiştirme

Şekil 13'de görüldüğ̈̈ gibi optimizasyon sonrası hidrolik pres gövdesi emniyet katsayısı çoğu bölgede oldukça yüksek değerde elde edilmiştir. 


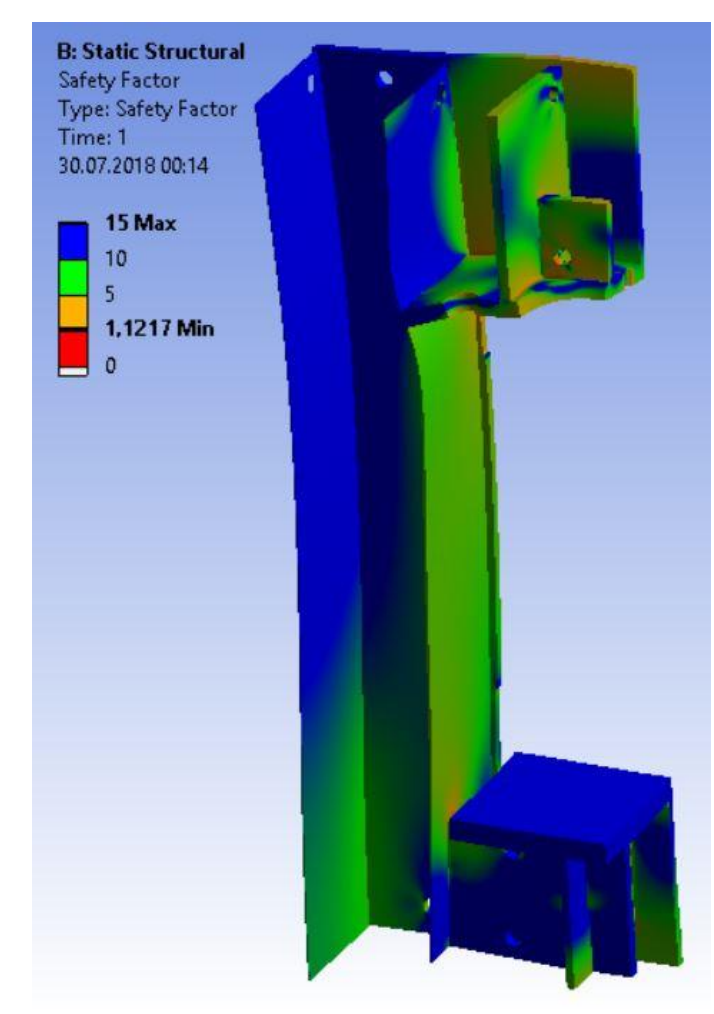

Şekil 13. Optimizasyon sonrası hidrolik pres gövdesi emniyet katsaylsı

Yapılan kalınlık optimizasyonun detayları Tablo-3’te verilmiştir.

Tablo 3. Kalınlı optimizasyonu

\begin{tabular}{lcc}
\hline \multicolumn{1}{c}{ Parça } & Optimizasyondan önce & Optimizasyondan sonra \\
\hline Üst uzun feder & $40 \mathrm{~mm}$ & $40 \mathrm{~mm}$ \\
\hline Üst kısa feder & $40 \mathrm{~mm}$ & $40 \mathrm{~mm}$ \\
\hline Gövde & $40 \mathrm{~mm}$ & $35 \mathrm{~mm}$ \\
\hline Üst silindir plakası & $60 \mathrm{~mm}$ & $60 \mathrm{~mm}$ \\
\hline Yan iç duvar & $15 \mathrm{~mm}$ & $10 \mathrm{~mm}$ \\
\hline Yan diş duvar & $15 \mathrm{~mm}$ & $5 \mathrm{~mm}$ \\
\hline Alt uzun feder & $40 \mathrm{~mm}$ & $40 \mathrm{~mm}$ \\
\hline Alt kısa feder & $40 \mathrm{~mm}$ & $30 \mathrm{~mm}$ \\
\hline Tabla & $150 \mathrm{~mm}$ & $80 \mathrm{~mm}$ \\
\hline
\end{tabular}

Yapılan kalınlık optimizasyonu sonucu pres gövdesindeki değişiklikler Tablo-4'te verilmiştir. Yan dış duvar ve tabla parçalarında optimizasyon öncesi emniyet katsayısı oldukça yüksek değerde olduğu için, bu parçaların kalınlıkları daha fazla azaltılmıştır. Optimizasyon sonucu emniyet katsayısı önemli ölçüde değişmeden, daha önce kritik olamayan bölgelerdeki gerilme dağılımları artırılarak optimizasyon yapılmıştır. Yapısal analiz ve kalınlık optimizasyonu sonunda, 300 ton kapasiteli H tipi hidrolik presin ağırlığında \%24 oranında tasarruf elde edilmiştir. Böylece pres maliyeti düşürülmüştür. 
Tablo 4. Optimizasyondan önce ve sonra presin statik davranışı

\begin{tabular}{lclc}
\hline \multicolumn{1}{c}{ Optimizasyondan önce } & \multicolumn{2}{c}{ Optimizasyondan sonra } \\
\hline Gövde maksimum Von Mises gerilmesi & $185 \mathrm{MPa}$ & Gövde maksimum Von Mises gerilmesi & $195 \mathrm{MPa}$ \\
\hline Gövde minimum emniyet katsayısı & 1,27 & Gövde minimum emniyet katsayısı & 1,21 \\
\hline Gövde ağırlığı & $8280 \mathrm{~kg}$ & Gövde ağırlı̆̆ & $6296 \mathrm{~kg}$ \\
\hline
\end{tabular}

Hidrolik presler dünyada yıllardır kullanılmaktadır ve ülkemizde genel olarak tecrübi olarak imal edilmektedir. Mühendislik hesap ve analizleri olmadan tasarlanan ve imal edilen bu makinaların gereğinden fazla mukavemetli olduğu düşünülmektedir. Bu şekilde bir imalat yapılması öncelikle firmalara ve dolaylı yönden ülke ekonomisine zarar vermektedir. Bu çalışmada elde edilen sonuçların uygulanmasıyla, hem yeterince mukavemetli bir pres tasarımı yapılabilir hem de maliyetler düşürülebilir. Böylece ülkemizin mühendislik tasarımlarıyla üretim yapabilen bir ülke olma hedefine ulaşmada katkı sağlanarak diğer ülkelerle rekabet etme gücü artırılacaktır.

\section{SONUÇ}

$\mathrm{Bu}$ çalışmada hidrolik presin statik yükleme durumundaki gerilme dağılımı incelenmiştir. Pres gövdesinin statik analizleri yapılmış ve maksimum Von Mises gerilme bölgeleri, emniyet katsayıları, yer değiştirmeleri ve optimizasyon yapılması gereken bölgeler belirlenmiştir. Yapısal analiz çalışmasının sonunda presi oluşturan parçaların kalınlık optimizasyonu yapılmış ve elde edilen sonuçlar geometri ve mukavemet bakımından presin ilk hali ile kıyaslanmıştır.

Çalışma sonunda;

Çalışmada presin statik yükleme durumunda pres gövdesi üzerindeki gerilmeler, emniyet katsayıları ve yer değiştirme sonuçları elde edilmiştir.

> Presin kalınlık optimizasyonu yapılmış, geometri ve mukavemet bakımından önceki modelle farklılıkları verilmiştir.

Yapısal analiz ve kalınlık optimizasyonu sonucunda, 300 ton kapasiteli $\mathrm{H}$ tipi hidrolik pres $\% 24$ oranında hafifletilmiştir ve böylece pres maliyeti düşürülmüştür.

> Yapılan bu çalışmada elde edilen sonuçların gerçek çalışmalarda uygulanabileceğini, ayrıca bu çalışmanın benzer çalışmalara ve literatüre 1şık tutacağını söylemek mümkündür.

\section{KAYNAKLAR}

[1] H.Ç. Sezgen, "H Tipi Hidrolik Presin Yapısal Analizi, Optimizasyonu ve Konum Kontrolü", Yüksek Lisans Tezi, Necmettin Erbakan Üniversitesi, Konya, Türkiye, 2016.

[2] S. Köseler, İ. Yüksel ve E.E. Topçu, "Üç Etkili, Yüksek Hızlı Bir Hidrolik Presin Tasarımı ve Analizi,” Uluslararası Katılımlı VII. Ulusal Hidrolik Pnömatik Kongresi, İstanbul, ss. 689-699, 2014.

[3] M. Zahalka, "Modal Analysis of Hydraulic Press Frames for Open Die Forging", Procedia Engineering, vol. 69, pp. 1070-1075, 2014. 
[4] L. Dejun, Li Peiwu, Guan Yanjin and Xie Chunlei, "Finite Element Analysis of Welded Sheet Frame of 22mn Hydraulic Press", Journal of Plasticity Engineering, 1995.

[5] Hidrolik Devre Elemanları ve Uygulama Teknikleri TMMOB Yayın No: 292, 2001.

[6] E. Koç, E. Ünver and H. Öztürk, "Design, manufacture and performance research of double acting hydraulic press," Journal of Engineers and Machinery, vol. 31, no. 367, pp. 23-30, 1990.

[7] M. Küçük, "Hidrolik ve Pnömatik,” M.E.B. Yayınları, 2003.

[8] İ. Karacan, "Endüstriyel Hidrolik," Gazi Üniversitesi Yayınları, Ankara, 1983.

[9] Y. Xiu-ping, Z. Sheng-fa and C. Xiao-cun, "Structural design of hydraulic press with finite element method", Heavy Machinery, 2003.

[10] O.Arslan, "Bir Eksantrik Pres Gövdesinin ANSYS ile Analizi," Bitirme Tezi, Dokuz Eylül Üniversitesi Makine Mühendisliği Bölümü, 2009.

[11] O.Yağbasan, "C Tipi Bir Pres Gövdesinin Sonlu Elemanlar Yöntemi ile Analizi," Yüksek Lisans Tezi, Eskişehir Osmangazi Üniversitesi Makine Mühendisliği Anabilim Dalı, 2010.

[12] G.Kutay, "Makina İmalatçıları İçin Temel Mukavemet Değerleri”, TMMOB Makine Mühendisleri Odası Yayınları, Yayın no: 156, Ankara, 1993. 